\title{
Invasive fungal infections in Canada from 1992 to 1994
}

\author{
LE Nicolle MD FRCPC ${ }^{1}$, C Rotstein MD FRCPC ${ }^{2}$, AM Bourgault MD FRCPC ${ }^{3}$, G St-Germain BSc ${ }^{4}$, \\ G Garber MD FRCPC ${ }^{5}$, and the Canadian Infectious Diseases Society Invasive Fungal Registry
}

LE Nicolle, C Rotstein, AM Bourgault, G St-Germain, G Garber, Canadian Infectious Diseases Society Invasive Fungal Registry. Invasive fungal infections in Canada from 1992 to 1994. Can J Infect Dis 1998;9(6):347-352.

PURPOSE: To describe the frequency, characteristics and impact of invasive fungal infection in Canada.

METHODS: Nominal case reporting with standardized data collection from selected sites across Canada. Cases were found primarily through laboratory review with supplementation by record review and clinical surveillance at some sites.

RESULTS: The frequency of invasive fungal infection varied from 3.54 to 6.64/100,000 population per year. Candida species were responsible for $66 \%$ of all reports; $80 \%$ of candidal infections were bloodstream isolates. Crytococcus neoformans, Aspergillus species and Histoplasma capsulatum each accounted for $5 \%$ to $10 \%$ of cases, and all other organisms less than $5 \%$ each. Human immunodeficiency virus infection was an important comorbidity for cryptococcus and histoplasma infections, and was associated with increased mortality for only histoplasma infections. Geographical variation of histoplasma, blastomyces and coccidioidomyces infection was confirmed. Case fatality was high for all invasive fungal infections, except coccidioidomycosis, blastomycosis and sporotrichosis.

CONCLUSIONS: Candida species infections are the major pathogens in invasive fungal infections in Canada; all other species occur relatively infrequently. The potential for therapeutic intervention to limit mortality requires further assessment.

Key Words: Blastomycosis, Canada, Candida, Cryptococcosis, Fungal infections, Histoplasmosis

\section{Les infections fongiques envahissantes au Canada de 1992 à 1994}

BUT : Décrire la fréquence, les caractéristiques et l'impact des infections fongiques envahissantes au Canada.

MÉTHODES : Rapport de cas nominaux avec cueillette standardisée des données provenant de sites sélectionnés au Canada. Les cas ont été principalement identifiés par un survol des résultats d'analyses de laboratoire et des suppléments d'information ont été tirés des dossiers et des données de surveillance clinique de certains sites.

RÉSULTATS : La fréquence des infections fongiques envahissante a varié de 3,54 à 6,64/100 000 de population par année. L'espèce Candida a été responsable de $66 \%$ de tous les rapports; $80 \%$ des infections à Candida provenaient de spécimens sanguins. Cryptococcus neoformans le genre Aspergilus et Histoplasma capsulatum ont chacun représenté 5 à $10 \%$ des cas et tous les autres organismes pathogènes moins de $5 \%$ chacun. L'infection au virus de l'immunodéficience humaine s'est révélée une importante comorbidité avec l'infection à Cryptococcus et à Histoplasma et a été associée à une mortalité accrue dans les cas d'infections à Histoplasma seulement. La variation géographique des infections à His-

voir page suivante

\footnotetext{
${ }^{1}$ Department of Internal Medicine, University of Manitoba, Winnipeg, Manitoba; ${ }^{2}$ Section of Infectious Diseases, Department of Internal
} Medicine, McMaster University, Hamilton, Ontario; ${ }^{3}$ Department of Microbiology, St Luc Hospital; ${ }^{4}$ Laboratoire de sante publique du Quebec, Montreal, Quebec; ${ }^{5}$ Division of Infectious Diseases, Department of Medicine, University of Ottawa, Ottawa, Ontario

Correspondence: Dr LE Nicolle, Health Sciences Centre, MS673-820 Sherbrook Street, Winnipeg, Manitoba R3A 1R9. 
toplasma, à Blastomyces et à Coccidioidomyces a été confirmée. La mortalité a été plus élevée pour toutes les infections fongiques envahissantes, à l'exception de la coccidioidomycose, la blastomycose et la sporotrichose.

CONCLUSION : Le genre Candida a été le principal organisme pathogène incriminé dans les infections fongiques envahissantes au Canada. Toutes les autres espèces sont relativement rares. Le potentiel des interventions thérapeutiques en vue de limiter la mortalité sera fonction des études à venir.

$\mathrm{H}$ istorically, the study of invasive fungal infections has focused on the classic fungal infections such as blastomycosis, histoplasmosis, cryptococcosis and coccidioidomycosis (1). Increasing broad spectrum antimicrobial use and more intensely immunocompromised patients have promoted the emergence of Candida species and Aspergillus species as important clinical pathogens over the past decades $(2,3)$. The expansion of therapeutic options for fungal infection occasioned by the introduction of new classes of antifungal agents (4) and new formulations of amphotericin B (5) is an important advance. These expanded treatment options have also been an impetus to understand the epidemiology and impact of fungal infection more fully.

There is limited information describing experience with invasive fungal infections in Canada. The only comprehensive report was published almost 30 years ago (1), and more recent reports have been generally organism-specific (6-11). To gain a further understanding of the occurrence and importance of significant fungal infections in Canada in the 1990s, a case registry was developed to identify episodes of invasive fungal infection between March 1, 1992 and February 28, 1994, and explore issues relevant to the impact of the diseases. This paper presents observations from this nominal case reporting of invasive fungal infection supplemented, in some provinces, by provincial laboratory records.

\section{PATIENTS AND METHODS}

Patient identification: Patients were identified primarily through a review of records of hospital clinical microbiology laboratories and provincial reference laboratories. In some sites, this was supplemented by hospital record review or review of infectious diseases consultations. Completeness of case ascertainment varied by area. Three geographical areas, Manitoba, Hamilton and Ottawa, had the most complete coverage. In Manitoba, reporting was through systematic review of records via the reference provincial laboratory, clinical laboratories of all large (more than 100 beds) hospitals in the province and clinical infectious diseases consultations. In the Hamilton region, patients were identified through hospital laboratory identification and medical record review at all large teaching hospitals, and, in Ottawa, patients were identified through laboratory identification of fungal isolates for all hospitals. In Ontario, Alberta and British Columbia, three provinces without complete province-wide reporting, nominal case reporting was supplemented by a review of records of selected fungal species identified by the provincial laboratories during the reporting period. In Quebec, all patients were identified through hospital laboratories and through the Laboratoire de sante publique du Quebec, Montréal, Québec where data collection was centralized. Isolates of blastomyces, histoplasma, sporothrix and coccidioidomycosis were all referred to the pro- vincial reference laboratory, but referral of yeast and other fungi was variable.

Definitions: Any clinical case of histoplasmosis, blastomycosis, cryptococcosis, coccidioidomycosis, paracoccidioidomycosis, sporotrichosis or zygomycosis was considered an invasive fungal infection. For aspergillosis, evidence of invasive infection obtained through biopsy of any body system was necessary for enrolment. Patients with colonization alone were excluded. For candidal infection, invasive infection was defined as all cases of bloodstream infection, bone and joint infection, hepatosplenic candidiasis, and intra-abdominal infection or abscess with isolation of the organism by itself from peritoneal or abscess fluid. In addition, pulmonary or skin infection documented histologically, and yeast cultured from a normally sterile site (eg, eye) were included. Subjects with mucocutaneous or intertriginous candidal infection were excluded, and those with positive urine culture with or without an indwelling catheter were included only if there was evidence for upper urinary tract involvement, such as a fungus ball.

Sites of infection, patient comorbidities and treatment interventions were gathered by clinical record review. Clinical outcome at the end of therapy was recorded. Death was considered to be caused by fungal infection if the infection was believed to be the direct cause of death, whether or not there was significant underlying disease.

Data collection and analysis: Standardized data collection included patient demographical information, presenting symptoms, culture and histology results, and selected comorbidities and therapies. Records were reviewed centrally for completeness and accuracy, and all data were entered into a computer. Outcome was recorded as death within six months and, if death, attributable to fungal infection or not.

The initial analysis was a summary of all cases identified. Population-based estimates for selected organisms and geographical areas were calculated using 1991 Canadian census information. Geographical distribution of different fungal isolates was described, and outcome stratified by infecting organism. Association with selected comorbidities, particularly human immunodeficiency virus (HIV) infection, was analyzed. The limited surveillance for some geographical areas meant reporting bias was a possibility for some variables. For instance, the majority of cases reported from one province came from an institution serving primarily HIV patients. Data were analyzed separately for the three areas with most complete surveillance, where appropriate, to avoid potential bias in reporting from sites with less complete surveillance.

\section{RESULTS}

The number of cases of fungal infection identified is summarized by species in Table 1 . The three centres with the most complete case finding reported 224 ( $28 \%$ of total) of the cases. 
TABLE 1

Distribution by species of 787 cases of fungal infection reported from 1992 to 1994

\begin{tabular}{|c|c|c|c|c|c|c|}
\hline \multirow[b]{2}{*}{ Organism } & \multirow[b]{2}{*}{ Cases (\%) } & \multirow[b]{2}{*}{ Male (\%) } & \multicolumn{4}{|c|}{ Age (years) (\%) } \\
\hline & & & Younger than 2 & 2 to 19 & 20 to 65 & Older than 65 \\
\hline Candida species & $518(66)$ & 53 & 6.2 & 4.7 & 54 & 35 \\
\hline Aspergillus species & $60(7.6)$ & 68 & 0 & 8.8 & 70 & 21 \\
\hline Histoplasma capsulatum & $53(6.7)$ & 74 & 0 & 15 & 74 & 11 \\
\hline Sporothrix schenkii & $9(1.1)$ & 67 & 0 & 11 & 78 & 11 \\
\hline Zygomycetes & $7(0.9)$ & 71 & 0 & 0 & 100 & 0 \\
\hline Other* & $19(2.5)$ & 58 & 0 & 22 & 67 & 11 \\
\hline Total & 787 & 60 & 4.2 & 6.0 & 62 & 28 \\
\hline
\end{tabular}

*Includes Trichosporon species $(n=6)$, Pseudallescheria boydii $(n=4)$, Fusarium species $(n=2)$, Malassezia furfur $(n=2)$, Phialophora species $(n=2)$, and one of each Paecilomyces species, Nectria species and myectoma

With the exception of Coccidioides immitis and Candida species, fungal infections occurred more frequently in men. Almost two-thirds of cases were identified in adults aged 20 to 65 years. Candida species and $C$ immitis infection occurred disproportionately in older adults compared with other fungal infections. Only Candida species infections and one case of Cryptococcus neoformans were reported in young children.

Candida infections accounted for two-thirds of cases, and $415(80 \%)$ of these were candidemia. The candidemia cases have been analyzed in depth and will be reported separately. For the 103 candida cases without fungemia, 37 (36\%) were peritonitis, primarily patients on peritoneal dialysis, 17 (17\%) hepatosplenic disease, 14 (14\%) genitourinary infection, nine (9\%) biopsy documented disseminated infection without fungemia, nine (9\%) pulmonary infection, seven (7\%) empyema, three $(3 \%)$ bone and joint infection, three (3\%) intra-abdominal abscess, and one each skin abscesses, endophthalmitis, vascular graft infection and invasive esophageal infection.

C neoformans, Aspergillus species, and Histoplasma capsulatum each accounted for only $5 \%$ to $10 \%$ of cases. Of the cryptococcus cases, 40 (49\%) of 81 cases were meningitis alone, $24(30 \%)$ disseminated or fungemic, 12 (15\%) pulmonary alone, three (4\%) pulmonary and meningitis, and one each adrenal and genitourinary. Of the 60 cases of Aspergillus species reported, 46 (77\%) were pulmonary alone, six (10\%) disseminated, three (5\%) central nervous system, three (5\%) pulmonary and brain, and one each both pulmonary and heart, and rhinocerebral alone. of histoplasmosis cases, 26 (49\%) were pulmonary alone, 21 (40\%) disseminated, two mediastinal, two central nervous system, and one each pulmonary with adrenal and cervical node infection.

Blastomyces, coccidioides, sporothrix and zygomycetes each contributed only a small number of cases. For blastomycosis, 13 (54\%) cases were pulmonary only, seven (29\%) pulmonary with one or more of cutaneous, genitourinary or bone and joint sites involved, two disseminated with lymphatic and splenic involvement in addition to other sites, and one each bone and joint alone, and bone and joint with cutaneous involvement. Of coccidioidomycosis cases, 14 were pulmonary
TABLE 2

Population-based calculation of incidence of fungal infections

\begin{tabular}{lccc}
\hline $\begin{array}{l}\text { Geographical } \\
\text { area }\end{array}$ & All infections & $\begin{array}{c}\text { Rate/100,000/year } \\
\text { Aspergillus }\end{array}$ & Candida \\
\hline Ottawa region & 3.54 & 0.08 & 2.36 \\
Hamilton region & 6.64 & 0.45 & 5.04 \\
Manitoba & 5.63 & 0.04 & 4.22 \\
\hline
\end{tabular}

only, and one case each of pulmonary and central nervous system, peritonitis, and disseminated infection. Of sporotrichosis, seven infections were cutaneous, one was bone and joint, and one pulmonary. Of the cases of zygomycetes reported, three were rhinocerebral, three pulmonary and one disseminated infection.

Population-based estimates of invasive fungal infections are shown in Table 2. Estimates of yearly incidence are relatively consistent, varying from $3.54 / 100,000$ for Ottawa to $6.64 / 100,000$ for Hamilton, with 2.36 to $5.04 / 100,000$ for Candida species. Because Hamilton and Manitoba included active components of surveillance beyond laboratory review, the higher rates may be more accurate. For Aspergillus species infections, greater variation in rates was observed (Table 2), with a 10-fold difference between areas. The largest number of Aspergillus species cases was reported from Quebec, where the rate was $0.25 / 100,000 / y e a r$. This is substantially higher than Ottawa or Manitoba, even given the probability of underreporting in Quebec.

As anticipated, there was marked geographical variation in occurrence of cases of blastomycosis and histoplasmosis (Table 3). For blastomycosis, 19 of 24 cases occurred in individuals resident or visiting endemic areas, four cases had unknown exposures, and one had no known exposure. No blastomycosis cases were identified west of Manitoba. The blastomycosis cases were reported primarily for Manitoba, but of the 15 (63\% of total) cases of blastomycosis reported in Manitoba, eight lived in northern Ontario and were referred for treatment. Cases in Manitoba occurred in northern and 
TABLE 3

Estimates of provincial rates of selected fungal infections

\begin{tabular}{lccc}
\hline \multirow{2}{*}{$\begin{array}{c}\text { Region or } \\
\text { province }\end{array}$} & Blastomycosis & Histoplasmosis & Cryptococcosis \\
\hline Maritimes & 0.43 & 0.43 & 0.86 \\
Quebec & 0.37 & 2.76 & 1.89 \\
Ontario & $0.94-1.44^{*}$ & $0.59-1.24^{*}$ & $\mathrm{NA}$ \\
Manitoba & 3.21 & 0 & 0.92 \\
Saskatchewan & 0 & 0 & 0 \\
Alberta & 0 & 0.20 & 0.79 \\
British Columbia & 0 & 0.31 & 3.50 \\
\hline
\end{tabular}

* Range is estimated depending on extent of overlap between cases identified in registry and those identified through provincial laboratory. NA Not available

southwestern areas of the province, in addition to the previously well characterized endemic area in the eastern province along the Ontario border. There were two blastomycosis cases reported from Ontario, five from Quebec, and one each from New Brunswick and Nova Scotia. The provincial laboratory in Ontario reported 19 patients with isolates during the study; depending on the extent of overlap with registry cases, total numbers in Ontario, then, varied from 19 to 29. Neither the British Columbia nor Alberta provincial laboratories isolated Blastomyces dermatitidis from clinical specimens during the study.

For histoplasmosis, 28 of 53 cases occurred in individuals residing in endemic areas, seven had visited endemic areas, nine had no known exposure, and for nine cases exposure history was unknown. Of the histoplasmosis cases, 38 (72\%) were from Quebec, 12 from Ontario, two from the Maritimes and one from British Columbia. No histoplasma cases were reported on the prairies; the two cases from the Maritimes had both travelled to an endemic area. The cases of histoplasmosis reported from Quebec included six school children (16\% of Quebec cases) linked with an outbreak following a visit to bat caves in Mexico. The Ontario Provincial Laboratory, Toronto, Ontario reported 25 patients with $H$ capsulatum isolated over the two years. The British Columbia and Alberta provincial laboratories each reported only one additional case.

For coccidioidomycosis, 15 of 17 cases were reported in individuals with a history of travel to Arizona or southern California, and for two cases the travel history was unknown. Twelve $(71 \%)$ of the cases of coccidioidomycosis reported to the registry were from Western Canada, one case was identified in Ontario and four in Quebec. The provincial laboratory in Ontario reported no isolation of coccidioidomycosis, in British Columbia an additional nine cases were identified, and in Alberta an additional seven cases. Thus, the incidence of coccidioidomycosis in Western Canada was 1.07 to 1.77 per $1,000,000$ population compared with 0.10 per $1,000,000$ in central Canada and the Maritimes.

Selected comorbidities and steroid therapy are summarized in Table 4 for the three regions with the most complete surveillance and Quebec, where the potential for reporting bias was limited. Infection with Candida species, C neoformans, Aspergillus species and Zygomycetes species occurred in patients with a significant illness associated with immunodeficiency in over $50 \%$ of cases. $H$ capsulatum, B dermatitidis and $C$ immitis were less frequently associated with comorbidites. HIV was an important associated underlying illness only for cryptococcus or histoplasma infection. Presentation of illness differed for patients with or without HIV infection. For cases of cryptococcus, 13 (24\%) of 54 HIV patients presented with disseminated infection compared with none of 24 without HIV infection $(\mathrm{P}=0.005)$. For histoplasmosis, $16(84 \%)$ of 19 HIV cases presented with disseminated infection compared with five (15\%) of 34 without HIV infection $(\mathrm{P}<0.001)$.

The mortality from all causes at final (six month) followup, stratified by infecting organism, is summarized in Table 5. The case fatality rate by organism was similar for the three areas with most complete reporting and all registry cases. The highest mortality was associated with Aspergillus species and Zygomycetes species infection, consistent with previous reports (12). Mortality was low for sporotrichosis, coccidioidomycosis and blastomycosis. Fungal infection was judged to be directly responsible for death in over $50 \%$ of deaths for all organisms except Candida species. For cryptococcus, mortality was similar in those with or without HIV infection; 17 (31\%) of

TABLE 4

Number of cases with selected underlying diseases or receiving steroid therapy reported from Quebec, Manitoba, Hamilton and Ottawa

\begin{tabular}{|c|c|c|c|c|c|c|c|}
\hline \multirow[b]{2}{*}{ Organism } & \multicolumn{7}{|c|}{ Number with underlying factor $(\%)$} \\
\hline & HIV & Malignancy & Diabetes mellitus & Transplant & Granulocytopenia & Steroid therapy & Total cases \\
\hline Candida species & $5(2.6)$ & $125(65)$ & $47(25)$ & $14(7.3)$ & $68(36)$ & $71(37)$ & 191 \\
\hline Aspergillus species & $2(5.1)$ & $20(51)$ & 0 & $1(2.6)$ & $21(54)$ & $16(41)$ & 39 \\
\hline Histoplasma capsulatum & $12(29)$ & $4(9.7)$ & $3(7.3)$ & 0 & $7(17)$ & $2(4.9)$ & 41 \\
\hline Blastomyces dermatitidis & $1(5)$ & $2(10)$ & $2(10)$ & 0 & $1(5)$ & $1(5)$ & 20 \\
\hline Zygomycetes & 0 & $4(67)$ & $2(33)$ & 0 & $4(67)$ & $1(17)$ & 6 \\
\hline Other & 0 & $6(40)$ & 0 & $3(20)$ & $4(27)$ & $8(53)$ & 15 \\
\hline
\end{tabular}

HIV Human immunodeficiency virus 
TABLE 5

Case fatality rate in patients with fungal infection from 1992 to 1994

\begin{tabular}{lccc}
\hline & & Number deaths/total (\%) & \\
& Manitoba, Ottawa, Hamilton & All reported & Due to fungal infection \\
\hline Candida species & $79 / 171(46 \%)$ & $224 / 518(43 \%)$ & $87(39 \%)$ \\
Candida neoformans & $5 / 13(38 \%)$ & $25 / 80(31 \%)$ & $14(56 \%)$ \\
Aspergillus species & $4 / 5(80 \%)$ & $39 / 60(65 \%)$ & $33(85 \%)$ \\
Histoplasma capsulatum & $0 / 3$ & $12 / 53(23 \%)$ & $8(75 \%)$ \\
Blastomyces dermatitidis & $0 / 15$ & $2 / 24(8 \%)$ & $2(100 \%)$ \\
Candida immitis & $0 / 13$ & $0 / 17$ & 0 \\
Sporothrix schenkii & $1 / 3(33 \%)$ & $1 / 9(11 \%)$ & 0 \\
Zygomycetes & $0 / 0$ & $5 / 7(71 \%)$ & $5(100 \%)$ \\
Other & $2 / 7(29 \%)$ & $4 / 19(21 \%)$ & $3(75 \%)$ \\
\hline
\end{tabular}

54 and eight (31\%) of 26 . For histoplasma, nine (47\%) of 19 with HIV infection died and three ( $9 \%$ ) of 34 without HIV infection died $(\mathrm{P}=0.001)$.

\section{DISCUSSION}

This two-year prospective case series provides an overview of the frequency and some assessment of the impact of invasive fungal infections in Canada. Candida species are, overwhelmingly, the most frequent significant clinical infection. The contribution of any other species to the burden of fungal infection in Canada, based on these observations, is relatively small. Infection is, however, associated with a high case fatality ratio for many organisms, and death is largely attributable to the infection.

Only one-fifth of the candida infections identified in this series were not bloodstream associated. For nonfungemic cases, peritonitis was the most frequent clinical presentation, associated in many cases with peritoneal dialysis. This high proportion of fungemia cases may reflect a bias in case ascertainment because cases were primarily identified through laboratory review. Thus, a positive blood culture would be consistently identified, whereas a biopsy specimen for hepatosplenic disease may not have been identified if the diagnosis was made based on histology rather than culture. The proportion of nonfungemic cases was, however, relatively consistent, accounting for $16 \%$ to $33 \%$ of Candida species cases at all but one site. That site reported only $2.1 \%$ of isolates were nonfungemic.

Aspergillus species infection, as anticipated, was observed primarily in granulocytopenic or otherwise immunocompromised subjects. The incidence of aspergillosis was greater than histoplasmosis, blastomycosis or cryptococcosis. Most individuals died from their aspergillus infection. The mortality rate of $65 \%$ to $70 \%$ is similar to other reports (12). Variation in aspergillus infection rates may reflect the availability of high efficiency particulate air (HEPA) filtration facilities to manage patients with profound granulocytopenia. In Manitoba, where all such patients are handled in a HEPA-filtered unit, only one case was identified in two years. Rates were approximately 10 times higher in Hamilton and Quebec, where such units are not widely used. Ottawa, however, also had a low rate and did not manage patients in a HEPA unit. The hospital where such patients are managed in Ottawa is a rela- tively new facility, having been built in 1980, and this may explain the low rate of aspergillosis in this area.

These data confirm and expand previous reports of geographical variation of selected fungal infections across Canada (1). Reports from the 1950s and 1960s identified the St Lawrence River valley and Great Lakes basin in Ontario and Quebec as the only endemic focus of histoplasma infection in Canada (1). Histoplasma infections are not acquired in the prairie provinces or British Columbia (7), and are uncommon in the Maritimes. The highest incidence of histoplasmosis in the two years discussed here was in Quebec, but imported cases from Mexico contributed to this high frequency.

Blastomycosis infection was essentially limited to Manitoba and northern Ontario, and selected areas in Quebec $(1,6,11,12)$. Cases were not reported in the rest of western Canada, and rarely from Atlantic Canada. The five cases of blastomycosis reported from Quebec during these two years is consistent with 23 cases occurring in a 10 -year period previously reported (11). Cases occurring in Manitoba were identified not just in the eastern part of the province bordering Ontario, but also in the north and southwest (13). Manitoba had the highest provincial incidence of blastomycosis, but this is misleading because the large unexposed population in southern Ontario decreases the Ontario provincial incidence. If the population of northern Ontario alone is used as denominator (estimated 772,835 ), the incidence in northern Ontario is 24.6 to 37.5 per million.

This report also identifies geographical variation in incidence of coccidiodomycosis within Canada (9). Because coccidioidomycosis is not endemic anywhere in Canada, the observation of geographical variation is a reflection of social behaviour. Western Canadians are more likely to visit the southwestern United States for winter vacation, whereas those from eastern Canada are more likely to winter in Florida. Thus, coccidiodomycosis occurs primarily in western Canada. The western Canadian rate of 1.1 to 1.8 per million population compares with the Arizona incidence of 70 per million in the same reporting period (14).

HIV infection occurred in only $8 \%$ of cases and had little impact on the total burden of invasive fungal infection. HIV infection is, however, an important comorbidity for histoplasma and cryptococcus infection. It was present in half of patients 
with cryptococcus infection and over one-quarter of individuals with histoplasma infection. Individuals with HIV and histoplasma usually presented with disseminated infection as previously reported (15), and are more likely to die. The variation in incidence of cryptococcal infections among provinces parallels Canadian differences in occurrence of HIV infection, where HIV seroprevalence and AIDS incidence are highest in British Columbia, Quebec and Ontario (16).

\section{CONCLUSIONS}

The observations from this nominal case reporting of invasive fungal infections provide important information relevant to Canada. The relative importance of different species in the total burden of severe fungal infections is documented, as is the substantial mortality associated with most fungal infections. These data serve as a basis for further characterization of geographical variation, costs of management of invasive fungal infections, identifying improved approaches for treatment and defining priorities in this area.

\section{REFERENCES}

1. Ajello L. A comparative study of the pulmonary mycoses of Canada and the United States. Public Health Rep 1969;84:869-77.

2. Edwards JE Jr. Candida species. In: Mandell GL, Bennett JE, Dolin R, eds. Principles and Practice of Infectious Disease, 4th edn. New York: Churchill Livingston, 1995:2289-306.

3. Bennett JE. Aspergillus species, In: Mandell GL, Bennett JE, Dolin R, eds. Principles and Practice of Infectious Disease, 4th edn. New York: Churchill Livingston, 1995:2306-11.

4. Kauffman CA. Role of azoles in antifungal therapy. Clin Infect Dis 1996;22(Suppl 2):S148-53.

5. Hiemenz JW, Walsh TJ. Lipid formulations of amphotercin $B_{1}$. Recent progress and future directions. Clin Infect Dis 1996;22(Suppl 2):S133-44.

6. Kane J, Righter J, Krajden S, Leiter RS. Blastomycosis: a new endemic focus in Canada. Can Med Assoc J 1983;129:728-31.

7. Taylor GD, Ganning EA, Gerguson JP, Jewell LD, Dekhon AS. Disseminated histoplasmosis in a non-endemic area. Can Med Assoc J 1985;133:763-5.

8. Sekhon AS, Bannerjee SM, Mielke BM, Idikio H, Wood G, Dixon JMS. Current status of cryptococcosis in Canada. Mycosis 1990;33:73-80.
ACKNOWLEDGEMENTS: Members of the Canadian Infectious Diseases Society Fungal Registry include Dr Lynn Johnston and Dr Wally Schlech, Halifax, Nova Scotia; Dr G William Thompson, Moncton, New Brunswick; Dr Chau Nguyen, St Johns, New Brunswick; Dr Anne-Marie Bourgault and M Guy Saint-Germain, Laboratoire de sante publique du Quebec, Montreal, Quebec; Dr Gary Garber and Dr Baldwin Toye, Ottawa, Ontario; Dr Gerald Evans, Kingston, Ontario; Dr Donald Low, Dr John Conly and Dr Sharon Walmsley, Toronto, Ontario; Dr Daniel Gregson, London, Ontario; Dr Coleman Rotstein, Hamilton, Ontario; Dr J Summerbell, Ontario Provincial Laboratory, Toronto, Ontario; Dr Lindsay Nicolle and Dr Godfrey Harding, Winnipeg, Manitoba; Dr Kurt Williams, Saskatoon, Saskatchewan; Dr Thomas Louie, Calgary, Alberta; Dr Robert Rennie, Northern Alberta Provincial Laboratory, Edmonton, Alberta; Dr Peter Phillips, British Columbia.

This study was funded through a grant from the Pharmaceuticals Group of Pfizer Canada Incorporated. We acknowledge the important assistance of Steve Ioannou of Pfizer Canada Inc and Roxanne Mirander of SciAn Clinical, Etobicoke, Ontario, in data analysis.

9. Sekhon AS, Isaac-Renton J, Dixon JMS, Stein L, Sims HV. Review of human and animal cases of coccidioidomycosis diagnosed in Canada. Mycopathologia 1991;113:1-10.

10. Carr MM, Fielding JC, Sibbald G, Freiberg A. Sporotrichosis of the hand: An urban experience. J Hand Surg 1995;20A:66-70.

11. St-Germain G, Murray G, Duperval R. Blastomycosis in Quebec (1981-90): Report of 23 cases and review of published cases from Quebec. Can J Infect Dis 1993;4:89-94.

12. Denning DW. Therapeutic outcome in invasive aspergillosis. Clin Infect Dis 1996;23:608-15.

13. MacDonald PB, Black GB, MacKenzie R. Orthopaedic manifestations of blastomycosis. J Bone Joint Surg 1990;71A:860-4.

14. Coccidioidomycosis Arizona 1990-1995. Morb Mortal Wkly Rep 1996;45:1069-72.

15. Sarosi GA, Johnson PC. Disseminated histoplasmosis in patients infected with human immunodeficiency virus. Clin Infect Dis 1992;14(Suppl 1):S60-7.

16. Quarterly surveillance update: AIDS in Canada. Ottawa: Division of HIV/AIDS Surveillance, Bureau of HIV/AIDS and STD, Laboratory Centre for Disease Control, Health Canada, 1996. 


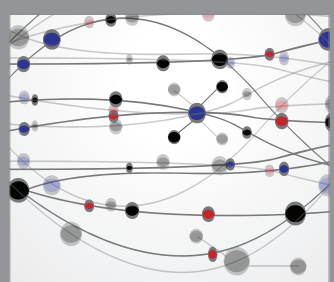

The Scientific World Journal
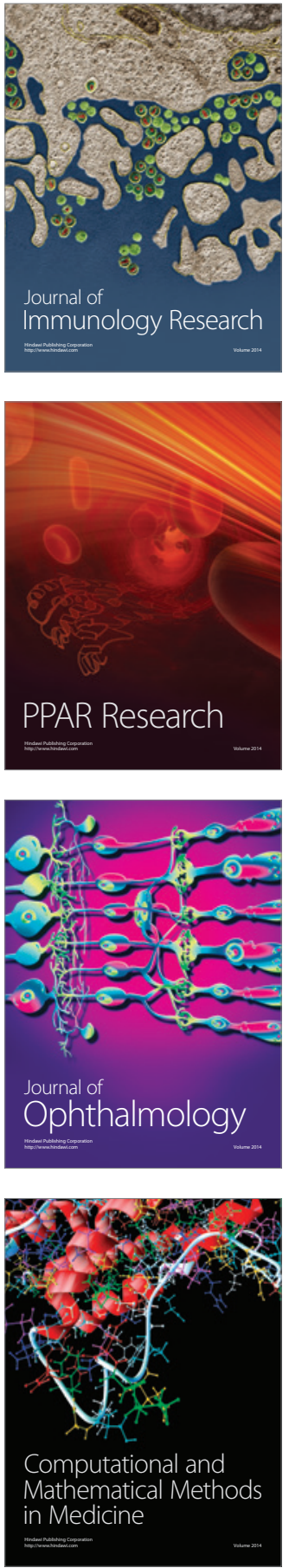

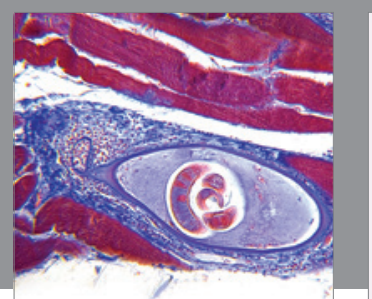

Gastroenterology Research and Practice

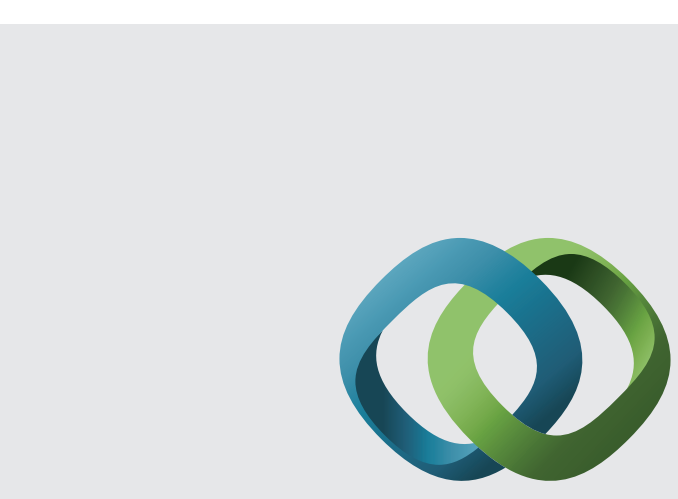

\section{Hindawi}

Submit your manuscripts at

http://www.hindawi.com
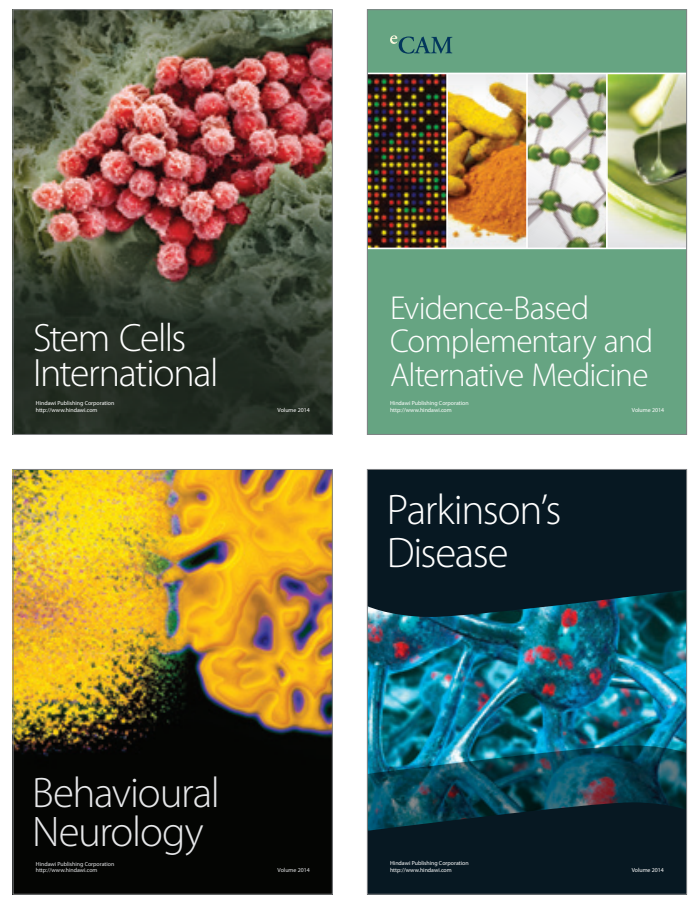
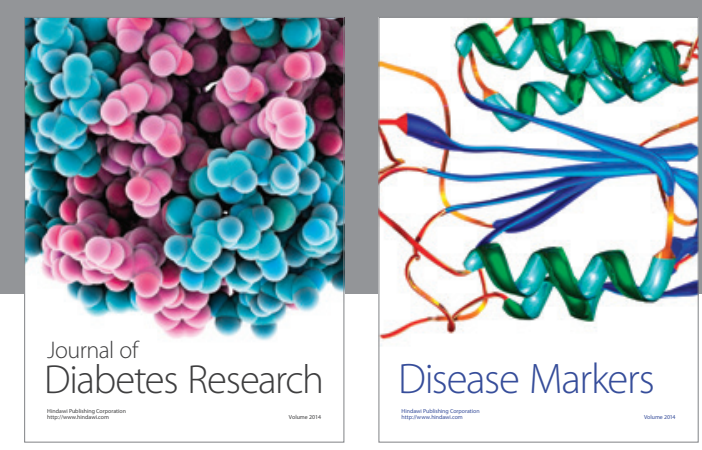

Disease Markers
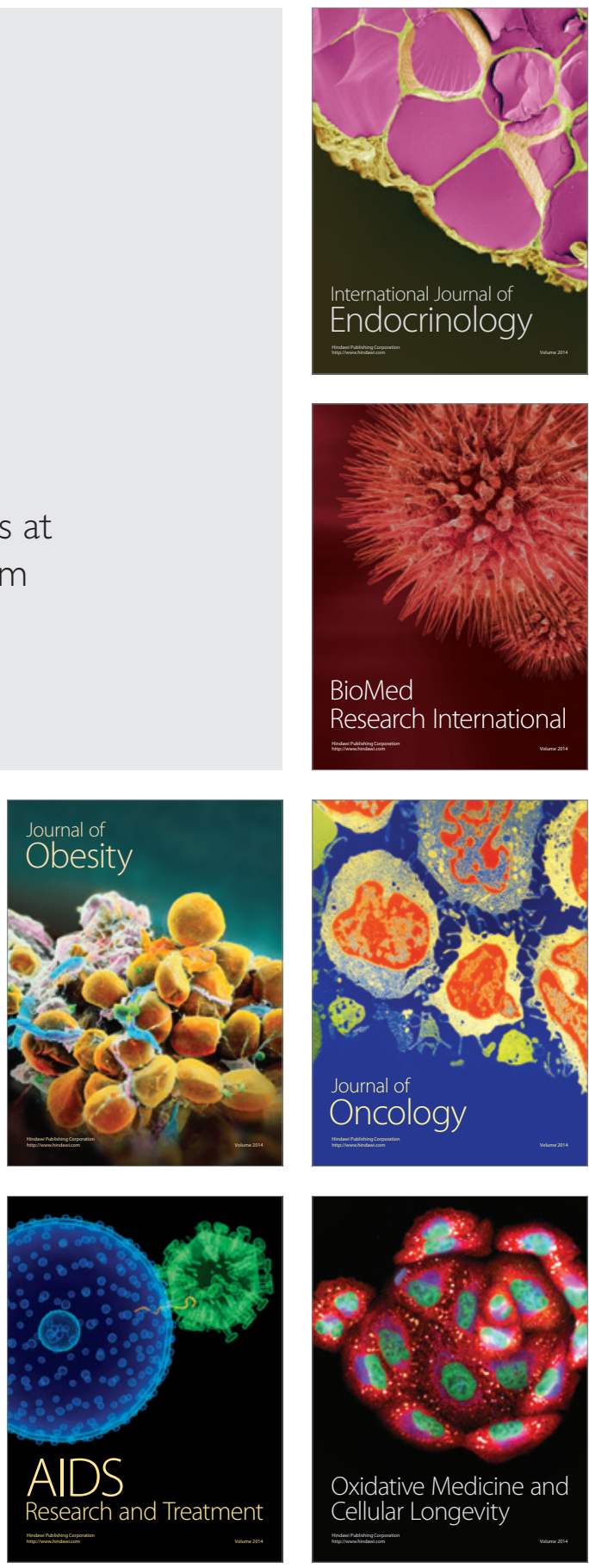